\title{
Business Analytics untuk Perguruan Tinggi: Studi Kasus Atas Pembukaan Program Studi Baru di UHAMKA
}

\author{
Nuryadi Wijiharjono \\ Universitas Muhammadiyah Prof. Dr, Hamka (UHAMKA) \\ Email: nuryadiwijiharjono@yahoo.com \\ ORCID: https://orcid.org/0000-0003-0089-7586
}

\begin{abstract}
$\underline{\text { Abstract }}$
This title of article is Business Analytics for Higher Education Institutions. By taking a case study at the Universitas Muhammadiyah Prof. Dr. Hamka, this article aims to analyze and provide recommendations for the plan to establish a new academic of undergraduate degree program. Analysis of the institutional and technical environment that affects the legitimacy and sustainability of the university. This study uses the SWOT analysis methode in the perspective of Business Analytics, where data availability plays a key role.

Keywords: Muhammadiyah, business analytics, logistics.

$\underline{\text { Abstrak }}$

Dengan mengambil studi kasus di Universitas Muhammadiyah Prof. Dr. Hamka, artikel ini bertujuan untuk menganalisis dan memberikan rekomendasi terhadap rencana pembukaan program studi baru. Analisis difokuskan pada lingkungan institusional dan lingkungan teknis yang memengaruhi legitimasi dan keberlangsungan perguruan tinggi tersebut. Penelitian ini menggunakan metode analisis SWOT dalam perspektif Business Analytics, di mana ketersediaan data memegang peranan kunci.
\end{abstract}

Kata kunci: Muhammadiyah, business analytics, logistik. 


\section{PENDAHULUAN}

Kajian ini berawal untuk sebuah proposal pembukaan program studi baru. ${ }^{1}$ Hampir seluruh aspek kehidupan manusia saat ini berubah secara radikal. Perubahan adalah sebuah keniscayan sejarah. Apalagi di masa kesulitan ekonomi akibat pandemi Covid-19 yang sudah berlangsung lama. Menurut Presiden Joko Widodo (Jokowi), yang paling siap menghadapi perubahan global yang sangat cepat adalah perguruan tinggi atau universitas. Ia menegaskan, mestinya kita berani mengubah fakultas ekonomi jadi misalnya fakultas atau jurusan logistics managment, retail menagement, toko online atau online store. Karena memang dunia sudah berubah. ${ }^{2}$ Dengan perkembangan teknologi saat ini, transaksi bisnis global sudah berlangsung secara real time 24 jam seminggu tanpa henti. Di balik transaksi itu, dibutuhkan dukungan sistem logistik yang mampu menjamin barang dari produsen sampai kepada konsumen dengan utuh dan tepat waktu. ${ }^{3}$

Berdasarkan survei Logistics Performance Index (LPI) yang dilakukan oleh Bank Dunia (2018), Indonesia berada pada peringkat ke-46 dari 160 negara yang disurvei. Dibandingkan dengan beberapa negara tetangga sesama anggota ASEAN, Indonesia masih berada di bawah Malaysia (41), Vietnam (39), Thailand (32), dan Singapura (7). Apalagi secara agregat, dari tahun 2012 sampai 2018 LPI Indonesia berada pada ranking ke-51 dari 167 negara. ${ }^{4}$ Bukan hanya biaya yang mahal pada sistem logistik di Indonesia, kompetensi sumber daya manusia (SDM) di bidang tersebut juga rendah akibat dari terbatasnya jumlah perguruan tinggi dan lembaga pelatihan di bidang logistik.

Logistik, dalam konteks manajemen rantai pasok (supply chain management), merupakan jawaban atas perubahan lingkungan bisnis yang dinamis, dan karena itu membutuhkan peran dari

\footnotetext{
${ }^{1}$ Materi untuk serial diskusi terbatas (FGD) yang berlangsung sejak April 2017, dan diperkaya sebagai masukan untuk rencana pembentukan program studi baru, Program Studi Logistik (Sarjana Logistik), di Fakultas Ekonomi dan Bisnis (FEB), Univerversitas Muhammadiyah Prof. Dr. Hamka (UHAMKA), Jakarta, Juni 2020. Pengajuan proposal akhirnya diurungkan karena adanya kebijakan moratorium maupun perubahan nomeklatur program studi.

${ }^{2}$ Sumber: https://setkab.go.id/antisipasi-perubahan-presiden-jokowi-dorong-perguruan-tinggi-berani-ubahfakultas-ekonomi/, diakses 7 Juni 2020.

${ }^{3}$ Zaroni, https://www.uii.ac.id/bisnis-online-dan-logistik-kian-dilirik-jadi-peluang-usaha/, diakses 14 Juni 2020.

${ }^{4}$ The Logistics Performance Index and Its Indicators. 2018. Washington: The International Bank for Reconstruction and Development/The World Bank. https://lpi.worldbank.org/report, diakeses 15 Juni 2020.
} 
perguruan tinggi. Beberapa universitas terkemuka membentuk pusat-pusat riset maupun program studi (departemen). Stanford University misalnya, bersama Endhoven University of Technology dan The Hongkong University of Science and Technology (HKUST) membentuk Global Supply Chain Management Forum. Sedangkan Massachusetts Institut of Technology (MIT) mendirikan MIT Center for Transportation \& Logistics, dan masih banyak lagi yang lainnya.

Di era new normal, sebuah istilah yang pertama kali muncul dalam kajian bisnis dan ekonomi sejak awal 2009-an, yang merujuk pada krisis finansial di Amerika Serikat 2007-2008 dan disusul resesi global 2008-2012. Ketika itu banyak perusahaan berkelas dunia terguncang dan bahkan tumbang. Apalagi saat ini, hanya sedikit kegiatan bisnis global yang benar-benar mampu bertahan. Mereka antara lain adalah perusahaan yang bergerak dalam bidang rantai pasok dan logistik berbasis teknologi informasi, seperti Amazon di Amerika Serikat dan Alibaba di China. Bahkan kedua perusahaan e-commerce raksasa dunia tersebut, di samping meraup banyak keuntungan di masa pandemik, mereka juga merekrut puluhan ribu karyawan baru seiring dengan meningkatnya penjualan melalui online. ${ }^{5}$ Artinya, bidang logistik dan rantai pasok berbasis teknologi informasi terbukti teruji di masa new normal ekonomi akibat pandemi global tersebut.

\section{METODE}

Untuk memperoleh pemahaman yang komprehensip sebagai analisis yang diharapkan dapat menghasilkan rekomendasi (prescriptive analytics), terutama untuk pengambilan keputusan dan perencanaan stategis (strategic planning) universitas, kajian tentang pembukaan program studi baru (Sarjana Logistik) ini menggunakan metode SWOT Analysis dalam perspektif Business Analytics. Menghadapi ketidakpastian, pendekatan Business Analytics merupakan suatu keharusan. ${ }^{6}$ Apalagi bagi sebuah perguruan tinggi swasta yang, secara manajerial, memiliki kemiripan tata-kelola dengan social enterprise. Artinya, data harus cepat dibaca dan diberi makna (data science) dengan segera sesuai dengan perkembangan dan kebutuhan pemangku kepentingan (stakeholder).

\footnotetext{
${ }^{5}$ Reeves, Martin, Harvard Business Riview, 10 Maret 2020.

${ }^{6}$ Lihat, misalnya: Pochiraju dan Seshadri (Editors). (2019). Essentials of Business Analytics: An Introduction to the Methodology and its Applications. Springer Nature Switzerland.
}

Business Analytics untuk Perguruan Tinggi...[Nuryadi Wijiharjono] 


\section{HASIL DAN PEMBAHASAN}

\section{Keunggulan dan Karakteristik Program Studi Logistik FEB-UHAMKA}

Berdasarkan hasil Analisis SWOT dan perspektif Business Analytics, maka keunggulan dan karakteristik program studi (Sarjana Logistik) yang diusulkan FEB-UHAMKA dapat digambarkan sebagai berikut:

1) Pendidikan fokus pada sistem logistik halal dalam konteks rantai pasok (supply chain) berbasis teknologi informasi.

2) Kurikulum program studi dirancang agar lulusannya: (a) memiliki kompetensi di bidang logistik dan rantai pasok halal; (b) berkepribadian luhur sesuai dengan Pancasila dan tujuan pembangunan nasional.

3) Mahasiswa dipersiapkan untuk mampu mengikuti sertifikasi profesi logistik dan rantai pasok, baik pada level operasional maupun managerial.

4) Proses pembelajaran seimbang antara teori dan praktik pada bidang logistik dan rantai pasok berbasis syariah.

5) Rancangan laboratorium logistik dan e-commerce yang moderen dan terintegrasi dengan rintisan seperti koperasi, bank mini, laboratorium kewirausahaan sosial dan filantropi Islam (LKSFI) untuk mendukung capaian pembelajaran, khususnya untuk membangun startup bisnis logistik halal.

6) Pelaksanaan praktek magang didukung oleh dunia industri dan perusahaan-perusahaan logistik nasional yang sudah berkomitmen bekerja sama dengan FEB-UHAMKA.

\section{Kurikulum Program Studi Sarjana Logistik FEB-UHAMKA}

\section{1) Landasan Filosofis dan Rumpun Keilmuan}

Secara filosofis, kompleksitas keilmuan dapat disederhanakan melalui perumpamaan sebuah pohon. Dengan perumpamaan itu, dasar keilmuan logistik (baca: Logistika) dapat dipahami melalui serangkaian pertanyaan berikut ini. Pertama, pohon apa itu dan apa cirikhasnya sehingga membedakannya dari pohon yang lain (ontologis)? Kedua, bagaima cara tumbuh dan berkembang pohon tersebut sehingga berbuah (epistemologis)? Ketiga, 
bagaimana memanfaatkannya secara praktis berdasarkan sistem nilai yang berlaku (aksiologis)?

Melalui perumpamaan pohon tersebut, dan berdasarkan bahan kajian yang relevan, maka dasar keilmuan maupun rumpun keilmuan dapat dikembangkan menjadi rancangan kurikulum yang utuh (komprehensip) untuk mewujudkan profil lulusan dengan kualifikasi dan kompetensi yang diinginkan. Dengan demikian, kebutuhan akan sumber daya manusia (dosen dan tenaga kependidikan) untuk mengoperasikan kurikulum, dan sumber daya lainnya untuk menjamin keberlangsungan program studi dapat direncanakan.

Tujuan mengetahui ontologi logistik adalah untuk menemukan dan memahami esensi dari domain logistik, yang biasanya berisi tentang konsep, hubungan, aksioma, individu dan tuntutannya. Esensi dari domain logistik meliputi prosres, layanan, sumber daya, kinerja, persediaan, rantai pasok, dan masalah logistik. ${ }^{7}$ Maka jika ditanya tentang apa itu logistik, mayoritas praktisi logistik akan menjawab dengan mengatakan bahwa, "logistics is all about transporting something from a place of origin to a destination in a certain time and under certain conditions", so the key words "transport" , "something" , "place of origin", "destination", "time" and "conditions" are already hints to what type of concepts can be included in such a core ontology, regardless of its specific application in logistics. ${ }^{8}$

Secara epistemologis, menurut Kovacs dan Spens (2007) cara kerja pengetahuan (keilmuan) logistik dapat dijelaskan melalui bangunan teori logistik (logistics theory building). ${ }^{9}$ Sedangkan logistik sebagai sebuah disiplin ilmu, saat ini telah berkembang pesat, dan harus dilihat dalam konteks rantai pasok (supply chain) yang lebih kompleks (Ronald H. Ballou, 2007). ${ }^{10}$.Dalam konteks supply chain management, tanggung jawab etis dan pengaruhnya terhadap kinerja di bidang logistik menjadi masalah penting dalam dunia bisnis, baik di kalangan akademisi maupun praktisi. Perusahaan yang memiliki reputasi yang

\footnotetext{
${ }^{7}$ Hendi, H.I. et al., Logistics optimization using ontologies. Proceedings of ICCSA 2014. Normandie University, Le Havre, France, 23-26 June 2014.

${ }^{8}$ Daniele, L. dan Pires, L.F., An ontolological approach to logistics. https://ris.utwente.nl/ws/portalfiles/portal/5369237/iwei-workshop-daniele.pdf, diakses 17 Juni 2020.

9 Kovacs, G., dan Karen M. Spens. (2007). Logistics Theory Building, The Icfai Journal of Supply Chain Management, Vol. IV, No. 4.

${ }^{10}$ Ballou, R.H. (2007), The evolution and future of logistics and supply chain management, European Business Review, Vol. 19 Iss 4 pp. $332-348$.
} 
baik secara finansial juga berkinerja baik. Reputasi yang baik dibangun berdasarkan persepsi stakeholders atas tanggung jawab mereka terhadap seluruh proses bisnis yang didasarkan pada sistem nilai. Dalam hal ini manager logistik memegang peran penting. ${ }^{11}$

Secara aksiologis, dasar keilmuan logistik juga merujuk pada sistem nilai dan bahkan asumsi teleologis. Dalam asumsi teleologis, logistik bukan sekedar urusan produksi, perdagangan dan layanan maupun lokasi dan waktu, melainkan bisa melampaui proses logistik itu sendiri. ${ }^{12}$ Jadi, landasan aksiologi logistik untuk merujuk sistem nilai dapat bersumber dari asumsi teleologis. Asumsi itu beragantung pada tujuan jauh yang akan dicapai (ultimate goal), dan hal tersebut akan banyak dipengaruhi oleh pandangan-dunia (world view) pelakunya. Dalam konteks dasar keilmuan seperti itulah, sistem logistik halal seharusnya dibangun dan dikembangkan. Bukan karena kebutuhan pasar, melainkan terutama karena ada tujuan transendental.

\section{2) Kurikulum}

Kurikulum FEB-UHAMKA dirancang berdasarkan Konsep Merdeka Belajar dari Kementerian Pendidikan dan Kebudayaan Republik Indonesia (2020). Agar mampu menjadi sebuah Program Studi Logistik yang bermutu dan terpercaya dalam mengembangkan pengetahuan dan sistem logistik halal untuk mewujudkan kesejahteraan masyarakat dan tujuan pembangunan nasional, maka diperlukan rancangan kurikulum sebagai berikut:

\section{Tahun Pertama}

Perkuliahan difokuskan pada pendidikan kepribadian luhur (Pendidikan Agama, Pendidikan Pancasila dan Kewarganegaraan, Bahasa Indonesia, Al-Islam dan Kemuhammadiyahan) dan penguasaan ilmu alat seperti Matematika Bisnis, Statistika Logistik, Pengantar Akuntansi, Pengantar Ekonomika, Manajemen, Bahasa Asing (Inggris dan Mandarin), dan Komputer.

\footnotetext{
${ }^{11}$ Yusuf, Yahaya, dan Hawkins, Anya, Musa, Ahmed, Berishy, Nagham El, Schulze, Marion and Abubakar, Tijjani. (2014). Ethical supply chains: analysis, practices and performance measures. International Journal of Logistics Systems and Management, 17 (4). pp. 472-497.

12 Chabereka, M., dan Cezary Mańkowskib. (2017). Teleological assumptions in the process of identification and evaluation of best logistics practices. Transport Economics And Logistics, Research Journal of The University Of Gdańsk. Vol. 71, pp. 7-17.
} 
Kemudian di semester kedua pada tahun itu juga mahasiswa sudah mulai diperkenalkan dengan Manajemen Logistik dalam konteks supply chian management.

\section{Tahun Kedua}

Fokus perkuliahan pada pengetahuan dan keterampilan dasar yang terkait dengan operasional perusahaan logistik seperti Manajemen Keuangan Logistik, Akuntansi Biaya, MSDM Logistik, Transportasi Logistik, Pengelolaan Barang, Penyimpanan dan Penyaluran Barang, Pengawasan Barang, Pemeliharaan dan Perawatan Barang, Budaya Kerja dan K3, Pengadaan Barang, dan Jasa, Asuransi Logistik, Customer Service Logistik, Packaging dan Material Handling, Hukum Bisnis, Perpajakan, dan E-Commerce \& Logistik Halal

\section{Tahun Ketiga}

Fokus perkuliahan pada pengetahuan dan keterampilan manajerial (level manager) di bidang logistik dan rantai pasok (supply chain) dalam konteks bisnis global (internasional) seperti Kepabeanan dan Ekspor-Impor, Transportasi \& Freight Forwarding Internasional, Bisnis Internasional, Logistik Internasional, Manajemen Rantaio Pasok (SCM), Sistem Logistik Halal, Business Plan dan Startup Logistik Halal, Manajemen Pergudangan, Manajemen Persediaan, Manajemen Transportasi, Manajemen Pengadaan, Legal Drafting, Negosiasi dan Kumunikasi Bisnis, Sistem Informasi Logistik, Marketing Logistik, dan Halal Total Quality Manufacturing.

\section{Tahun Keempat}

Fokus pada magang (internship) dan penyelesaian kuliah, dan untuk itu mahasiswa dibekali dengan Metodologi Penelitian dan Teknik Penulisan Laporan (Tugas Akhir).

\section{Kesiapan Institusi dalam Perspektif Business Analytics}

Universitas Muhammadiyah Prof. Dr. Hamka (UHAMKA) merupakan perguruan tinggi yang didirikan oleh Persyarikatan Muhammadiyah. UHAMKA adalah perubahan bentuk dari IKIP Muhammadiyah Jakarta yang didirikan pada 18 November 1957. Pada 1988, IKIP Muhammadiyah Jakarta mendapat penghargaan internasional (Peace Messenger Certificate) yang diserahkan langsung oleh Sekjen Persyarikatan Bangsa-Bangsa (PBB) kepada rektor (Dr. H. Agustiar, MA) di Markas Besar PBB di New York, USA. Melalui Keputusan Dirjen Dikti 
Depdikbud Nomor 138/DIKTI/Kep/1997 tanggal 30 Mei 1997, IKIP Muhammadiyah Jakarta secara resmi berubah bentuk (konversi) menjadi UHAMKA.

Sejak tahun 2016, institusi UHAMKA memperoleh peringat A (Unggul) dalam Akreditasi Perguruan Tinggi (APT) dari Badan Akreditasi Nasional Perguruan Tinggi (BANPT). Pencapaian peringkat akreditasi institusi tersebut menunjukkan adanya pengakuan (rekognisi) atas kemampuan UHAMKA dalam menyelenggarakan pendidikan tinggi dari lembaga yang paling berwenang dan kredibel. Sebagai Perguruan Tinggi Muhammadiyah (PTM), UHAMKA juga memperoleh kepercayaan dari pemerintah dan masyarakat serta dunia industri atas kontribusinya dalam mencerdaskan kehidupan bangsa, sebagaimana diamanatkan oleh konstitusi.

UHAMKA dianugerahi dengan lokasi kampus yang strategis dan dukungan infrastruktur serta SDM yang, jika digerakkan dengan tepat secara kolektif-kolegial, akan menjadi bergairah dan gigih. Kunci kesuksesan jangka panjang sebuah organisasi maupun institusi bukan hanya bergantung pada kualifikasi dan kompetensi SDM, apalagi sekedar bakat, melainkan terutama ditentukan oleh kesabaran dan kegigihan setiap individu dari para penerusnya. ${ }^{13}$ Tidak banyak organisasi maupun institusi, baik lokal maupun nasional, bahkan internasional, yang mampu menciptakan lingkungan yang relatif kondusif bagi para anggotanya sehingga sebagian dari mereka bersedia terlibat dan bertekun diri dengan tulus untuk pencapaian tujuan berjangka panjang, seperti gambaran membudidayakan tanaman pohon yang baik (syajarah thayyibah). ${ }^{14}$

Singkatnya, dari beberapa aspek mendasar dalam Business Analytics seperti analisis pasar, analisis risiko, analisis kinerja dan SDM, analisis sistem pendukung yang tersedia, analisis media sosial dan web, termasuk optimalisasi peran badan pengembangan teknologi informasi (BPTI-Uhamka), dan Fakultas Teknik, memungkinkan UHAMKA mampu mengelola dan menyelenggarakan Program Studi Logistik secara berkelanjutan. Apalagi jika model perkuliahan "Merdeka Belajar" dapat diimplementasikan secara optimal, di mana mahasiswa dapat

\footnotetext{
${ }^{13}$ Duckworth, A. L., Peterson, C., Matthews, M. D., \& Kelly, D. R. (2007). Grit: Perseverance and Passion for LongTerm Goals. Journal of Personality and Social Psychology, 2007, Vol. 92, No. 6, 1087-1101.

${ }^{14}$ Tidakkah kamu perhatikan bagaimana Allah telah membuat perumpamaan kalimat yang baik seperti pohon yang baik, akarnya teguh dan cabangnya (menjulang) ke langit, pohon itu memberikan buahnya pada setiap musim dengan seizin Tuhannya. Allah membuat perumpamaan itu untuk manusia supaya mereka selalu ingat. (QS. Ibrahim [14]: 24-25).
} 
mengambil mata kuliah lintas program studi, niscaya program tersebut dapat menjawab kebutuhan pasar dan tujuan pembangunan nasional. Di samping itu, program tersebut juga pararel dengan harapan Presiden Jokowi kepada pimpinan perguruan tinggi, sebagaimana telah disebutkan di muka.

\section{KESIMPULAN}

Dalam perspektif Business Analytics, UHAMKA memiliki semua modal yang diperlukan untuk mampu menyelenggarakan Program Sarjana Logistik secara berkelanjutan. Munculnya kebijakan moratorium terhadap p embukaan program studi baru misalnya, bukanlah akhir dari perjuangan mencerdaskan kehidupan bangsa. Kesejarahan dan karakteristik UHAMKA sebagai Perguruan Tinggi Muhammadiyah (PTM), yang senantiasa loyal kepada negara dan selalu berkiprah berdasarkan peraturan perundang-undangan yang berlaku, justru memperkokoh legitimasi dan rekognisi.

Sebagai sebuah rekomendasi, terlepas dari adanya kebijakan moratorium pembukaan program studi, secara Business Analytics, di masa wabah Covid-19 dengan berbagai variannya, tidaklah tepat untuk membuka sebuah program studi baru. Sebaliknya, justru saatnya untuk berpikir reflektif tentang bagaimana agar UHAMKA tetap mampu menjaga dan meningkatkan mutu pengajaran dan pembelajaran (teaching university) sebagai wujud pelayanan prima kepada mahasiswa dan masyarakat. Semoga.

\section{REFERENSI}

Ballou, R.H. (2007), The evolution and future of logistics and supply chain management, European Business Review, Vol. 19 Iss 4 pp. 332 - 348.

Chabereka, M., dan Cezary Mańkowskib. (2017). Teleological assumptions in the process of identification and evaluation of best logistics practices. Transport Economics And Logistics, Research J ournal of The U niversity Of G dańsk. Vol. 71, pp. 7-17.

Daniele, L. dan Pires, L.F., An ontolological approach to logistics. https://ris.utwente.nl/ws/portalfiles/portal/5369237/iwei-workshop-daniele.pdf, diakses 17 Juni 2020. 
Duckworth, A. L., Peterson, C., Matthews, M. D., \& Kelly, D. R. (2007). Grit: Perseverance and Passion for Long-Term Goals. Journal of Personality and Social Psychology, 2007, Vol. 92, No. 6, 1087-1101.

Hendi, H.I. et al., Logistics optimization using ontologies. Proceedings of ICCSA 2014. Normandie University, Le Havre, Franc, 23-26 June 2014

Kovacs, G., dan Karen M. Spens. (2007). Logistics Theory Building, The Icfai Journal of Supply Chain Management, Vol. IV, No. 4.

Pochiraju, B. dan Sridhar Seshadri (Editors). (2019). Essentials of Business Analytics: An Introduction to the Methodology and its Applications. Springer Nature Switzerland.

Reeves, Martin, Harvard Business Riview, 10 Maret 2020.

The Logistics Performance Index and Its Indicators. 2018. Washington: The International Bank for Reconstruction and Development/The World Bank. https://lpi.worldbank.org/report, diakeses 15 Juni 2020.

Yusuf, Yahaya, dan Hawkins, Anya, Musa, Ahmed, Berishy, Nagham El, Schulze, Marion and Abubakar, Tijjani. (2014). Ethical supply chains: analysis, practices and performance measures. International Journal of Logistics Systems and Management, 17 (4). pp. 472497. 